\title{
Vascular endothelial dysfunction in sickle cell disease by brachial artery flow mediated dilatation
}

\author{
Pranav Kumar Raghuwanshi', Somnath Singh Raghuvanshi ${ }^{2}$ \\ ${ }^{1}$ Assistant Professor in Medicine, Department of Medicine, L N Medical College and Research Center, Bhopal (M.P.) India, ${ }^{2}$ Resident in \\ Medicine, Department of Medicine, Gandhi Medical College, Bhopal (M.P.), India
}

\section{A B S T R A C T}

Objective: The present study was conducted aiming to assess endothelial function in sickle cell disease (SS), sickle cell trait(SA) and compare to endothelial dysfunction between sickle cell anemia (SS), sickle cell trait (SA) cases and control (AA) patients to evaluate correlation of endothelial dysfunction. Methods: The study population comprised of, total 25 cases having sickle cell disease and sickle cell trait and 25 age and sex matched normal control. Endothelial dysfunction as assessed by brachial artery flow mediated dilatation by colour Doppler (non-invasive method)by using Siemens Sonoline 500. Statistical analysis was performed using Software Statistical Package for Social Sciences (SPSS) version 20, and $P$ value of less than 0.05 was considered as statistically significant at $95 \%$ confidence intervals. Results: Significant difference were observed in FMD (flow mediated vasodilatation) in case and control group ( $<<0.05)$, also significant difference was demonstrated between AS and SS group. Conclusion: The percentage of flow mediated dilatation of vessel is a marker of endothelial function was significantly lower in cases as compared to controls and was also lower in AS \& SS when compared to control group \& significantly lower in SS group than AS group.

Key words: Sickle cell disease, Sickle cell trait, Flow Mediated Vasodilatation

\section{INTRODUCTION}

Endothelium once believed to be an inert edge between artery and blood, is now recognized as organ per se. Vascular endothelium performs an array of homeostatic functions within normal blood vessels and endothelium cells plays a critical role through endothelium derived relaxing factor (EDRF), which was identified as nitric oxide (NO) by Flavahan NA (1992). ${ }^{1}$ Vaso-occlusive crisis is a characteristic manifestation of sickle cell disease (SCD). According to Lonsdorfer J (1983), the interactions between sickle red blood cells (SSRBCs) and the endothelium may contribute to the pathogenesis of vaso-occlusive crisis. Sickle erythrocytes may occlude microvessels directly by adhering or indirectly by altering endothelial functions such as endothelium-dependent vasodilation. Thus, enhanced interactions between SSRBCs and the vascular endothelium on one hand and abnormal vasomotor tone regulation on the other may contribute synergistically to the occurrence of vessel in sickle cell disease. In vivo studies have identified specific hemodynamic conditions in the microcirculation of patients with SCD. During the intervals between crises, there is an increase in peripheral blood flow with a periodic microcirculatory flow pattern, which may compensate for the alterations in red blood cell rheology. Arteriolar diameter is increased during vaso-occlusive crisis as compared with steady state phases of the disease. Thus, the relationship between endothelial regulation of vascular tone and red blood cell rheology seems to play a key role in SCD. Sickle cell disease is a autosomal recessive disorder of structural haemoglobinopathy involving substitution of thiamine instead of glutamine in the $6^{\text {th }}$ position of $\beta$-chain. ${ }^{2}$ Average incidence of sickle cell disease is approximately $4.3 \%$ in India (Kar BC et al 1987). ${ }^{2}$ Endothelial dysfunction in sickle cell disease has been demonstrated by various workers by biochemical and physiological methods. 


\section{MATERIALS AND METHODS}

The present study was conducted was conducted in department of medicine and radio diagnosis L N Medical College and Research Center Bhopal Madhya Pradesh India. The study population comprised of, total 25 cases having sickle cell disease and sickle cell trait and 25 age and sex matched normal control.

\section{Inclusion criteria}

\section{For cases}

Cases included sickle cell disease (HbSS) and sickle cell trait (HbAS) both during crisis and steady phase. Twentyfive age and sex matched controls were also included accordingly in sickle cell anaemia and trait groups. The consent taken before study from all participants.

\section{For control}

Controls included subjects those who have no evidence of any disease clinically and belonging to the same age and sex group as the patients.

\section{Exclusion criteria}

For case includes the History of blood transfusion during last 3 months, History of treatment with vasodilators, hydroxyurea, History of smoking, History of Diabetes Mellitus, History of hypertension, Congestive cardiac failure, Renal insufficiency, Ischemic heart disease, Dyslipidemia, treatment with vasodilators, anti-inflammatory drugs, or hydroxyurea; and concomitant systemic disease.

\section{Flow mediated vasodilatation (FMD)}

Endothelial dysfunction as assessed by brachial artery flow mediated dilatation by colour Doppler (non-invasive method)by using Siemens Sonoline 500. The two reading were opted as follows, First - After the rest of 10 minutes, Second - After the forearm compression by pneumatic tourniquet at $200 \mathrm{mmHg}$ for five(5) minutes. The diameter of brachial artery were measured one and half minutes after the release of pressure. Scanned area was marked to measure the same segment of brachial artery repeatedly i.e. $1^{\text {st }}$ at rest, $2^{\text {nd }}$ after reactive hyperemeia. ${ }^{3,4}$

\section{Calculation of FMD\% (flow mediated dilatation)} Brachial. Artery diameter after hyperaemia - Brachial Artery diameter at rest/ Brachial Artery diameter at rest $\times 100$.

\section{Statistical analysis}

Statistical analysis was performed using Software Statistical Package for Social Sciences (SPSS) version 20, $\mathrm{T}$ test, chi-square test, and Chi-square trend for linear association were performed. P value of less than 0.05 was considered as statistically significant at $95 \%$ confidence intervals.

\section{RESULTS}

In control group majority of males (82.67\%) and females $(75 \%)$ were found in age $<30 \mathrm{yrs}$. The mean age of male and female were $24.41( \pm 6.59) \mathrm{yrs}$ and $25.00( \pm 7.56) \mathrm{yrs}$ respectively (Table 1$)$. The difference in mean age was statistically insignificant ( $p>0.05$ ) (Table 3). In sickle cell trait group majority of males $(85.7 \%)$ and females $(60 \%)$ were found in age $<30 \mathrm{yrs}$. The mean age of males and females were $24.00( \pm 7.32)$ yrs and $23.80( \pm 8.25)$ yrs respectively (Table 1$)$. The difference in mean age was statistically insignificant $(\mathrm{p}>0.05)$. In sickle cell disease group majority of males $(75 \%)$ and females $(80 \%)$ were found in age $<30 \mathrm{yrs}$ (Table 3). The mean age of male and female were $23.63( \pm 6.47)$ yrs and $21.80( \pm 6.87)$ yrs respectively (Table 1$)$. The difference in mean age was statistically insignificant $(\mathrm{p}>0.05)$ (Table 3$)$. In AS group majority of males $(85.7 \%)$ and females $(60 \%)$ were found in age $<30 \mathrm{yrs}$. The mean age of males and females were 24.00 $( \pm 7.32)$ yrs and $23.80( \pm 8.25)$ yrs respectively (Table 1$)$. The difference in mean age was statistically insignificant $(\mathrm{p}>0.05)$. In SS group majority of males $(75 \%)$ and females $(80 \%)$ were found in age $<30 \mathrm{yrs}$. The mean age of male and female were $23.63( \pm 6.47) \mathrm{yrs}$ and $21.80( \pm 6.87) \mathrm{yrs}$ respectively. The difference in mean age was statistically insignificant $(\mathrm{p}>0.05)$ (Table 3).

As compared to control group significant difference was observed in mean FMD (\%) in both trait \& disease group. $(\mathrm{p}<0.05)$, also significant difference was demonstrated between AS and SS group. In all age groups significant difference was observed in cases as compared to control group $(p<0.05)$ (Table 2). Significance difference was observed between male in case and control groups $(p<0.0001)$. Similar findings were observed between females $(p<0.0001$ as the male by FMD in both case and control group (Table 4).

\begin{tabular}{|c|c|c|c|c|c|c|c|c|c|}
\hline \multirow{2}{*}{$\begin{array}{l}\text { Age } \\
\text { Group (year) }\end{array}$} & \multicolumn{3}{|c|}{ Sickle cell trait (AS) } & \multicolumn{3}{|c|}{ Sickle cell disease (SS) } & \multicolumn{3}{|c|}{ Control } \\
\hline & $M(\%)$ & $F(\%)$ & $\mathrm{T}(\%)$ & $M(\%)$ & $F(\%)$ & $\mathrm{T}(\%)$ & M (\%) & $F(\%)$ & $\mathrm{T}(\%)$ \\
\hline$<20$ & $1(14.3)$ & $2(40)$ & $3(25)$ & $2(25)$ & $2(40)$ & $4(30.8)$ & $4(23.8)$ & $2(25)$ & $6(24)$ \\
\hline $20-29$ & $5(71.4)$ & $1(20)$ & $6(50)$ & $4(50)$ & $2(40)$ & $6(46.2)$ & $10(58.8)$ & $4(50)$ & $14(56)$ \\
\hline $30-39$ & $1(14.3)$ & $2(40)$ & $3(25)$ & $2(25)$ & $1(20)$ & $3(23)$ & $3(17.6)$ & $2(25)$ & $5(20)$ \\
\hline Total & 7 & 5 & 12 & 8 & 5 & 13 & 17 & 8 & 25 \\
\hline Mean $\pm S D$ & $24.00 \pm 7.32$ & $23.80 \pm 8.25$ & $23.92 \pm 7.35$ & $23.63 \pm 6.47$ & $21.60 \pm 6.87$ & $22.92 \pm 6.40$ & $24.41 \pm 6.59$ & $25.00 \pm 7.56$ & $24.60 \pm 6.76$ \\
\hline
\end{tabular}




\begin{tabular}{|c|c|c|c|}
\hline & Case & Control & $\mathbf{P}$ \\
\hline $\begin{array}{l}\text { Mean } \pm S D \\
(F M D \%)\end{array}$ & $\begin{array}{c}8.08 \pm 2.73 \\
(n=25)\end{array}$ & $\begin{array}{c}15.39 \pm 3.04 \\
(n=25)\end{array}$ & $\mathrm{P}<0.0001$ \\
\hline
\end{tabular}

\begin{tabular}{lccc}
\multicolumn{4}{l}{$\begin{array}{l}\text { Table 3: Correlation of endothelial dysfunction } \\
\text { in case compared to control according to age }\end{array}$} \\
\hline Age & $\begin{array}{c}\text { Case } \\
\text { Mean FMD\% }\end{array}$ & $\begin{array}{c}\text { Control } \\
\text { Mean FMD\% }\end{array}$ & P \\
\hline$<20$ & $8.00 \pm 2.33(n=7)$ & $16.16 \pm 1.71(n=6)$ & $P<0.05$ \\
$20-29$ & $7.81 \pm 2.83(n=12)$ & $15.05 \pm 3.40(n=14)$ & $P<0.05$ \\
$30-39$ & $8.71 \pm 3.33(n=6)$ & $15.42 \pm 3.57(n=5)$ & $P<0.05$ \\
\hline
\end{tabular}

\begin{tabular}{lccc}
\multicolumn{4}{l}{ Table 4: Correlation of endothelial dysfunction } \\
in case compared to control according to sex
\end{tabular}

\section{DISCUSSION}

Study included total 50 subjects equally divided between cases and controls. Cases included sickle cell disease (SS) and sickle cell trait (AS). Twenty-five age and sex matched controls were also included those who had no evidence of any disease clinically and belonging to the same age and sex group as the patients. Twenty-five sickle cell anaemia cases were studied and divided into 2 groups - sickle cell disease (HbSS) \& sickle cell trait (HbAS) which included 13 and 12 patients respectively. In the present mean flow mediated vasodilatation (FMD) $\%$, that is mean $\%$ increased in the lumen diameter of brachial artery after stress (ie., reactive hyperaemia), was significantly reduced in sickle cell anaemia cases $(8.08 \pm 2.73)$ as compared to control (15.39 \pm 3.04$), \mathrm{p}<0.0001$. Compared to control group (15.39 \pm 3.04) significant difference was observed in mean $\mathrm{FMD} \%$ in both sickle cell trait $(9.72 \pm 1.97)$ and sickle cell homozygous (SS) group $(6.56 \pm 2.50) \mathrm{p}<0.05$. FMD $\%$ was significantly lower in patients with steady phase as compared to control group $(8.42 \pm 0.99 \mathrm{v} / \mathrm{s} 15.39 \pm 3.04$ in SS group and $11.42 \pm 1.48$ $\mathrm{v} / \mathrm{s} 15.39 \pm 3.04$ in AS group. These findings corroborate with the works of Zawar SD et al (2002-03). ${ }^{5}$ They found that $\mathrm{FMD} \%$ was significantly lower in cases as compared to controls $(p<0.05)$. Results of the present study consistent with the work of Zawar SD et al. They found that endothelial dysfunction was significantly more in sickle cell anemia as compared to sickle cell trait cases. In all age groups significant reduction in mean $\mathrm{FMD} \%$ were observed in cases as compared to control group. according to Blum (2005). ${ }^{6}$ Flow mediated dilation (FMD) $\%$ was $4.57+/-4.11$ at steady state, compared with the control group FMD of 11.64+/- 7.69\% ( $\mathrm{p}<0.001)$., compared with control group FID of $24.17+/-11.87 \%(\mathrm{p}<$ 0.001) \& findings shoed reduction in FMD. A Aessopos (2007) \& Rambaran \& B Jiang $(2007)^{8}$ significant reduction in FMD in disease compare to control. Significant reduction in mean FMD $\%$ was observed between male in case and control. When compared to male and female in both case and control group no significant difference were observed. The conclusion drawn from the present study are as follows the percentage of flow mediated dilatation of vessel is a marker of endothelial function was significantly lower in cases as compared to controls and was also lower in AS \& SS when compared to control group \& significantly lower in SS group than AS group.

\section{ACKNOWLEDGEMENT}

We would like to cordially thank Department of Medicine and Radiodiagnosis L N Medical College and Research Bhopal supporting this study.

\section{REFERENCES}

1. Flavahan NA. Atherosclerosis or lipoprotein - induce endothelial dysfunction potential mechanism underlying reduction in EDRF/ NO activity. Circulation 1992; 85: 1927-1938.

2. Kar BC, Devi S, Dash KC and Das M. The sickle cell gene is widespread in India. Trans Roy Soc Trop Med \& Hyg 1987; 82: 273.

3. Takase B, Uehata A, Akima T, Nagai T, Nishioka T, Hamabe $A$, et al. Endothelial-dependent flow-mediated vasodilatation in coronary \& brachial arteries in suspected coronary artery disease. Am J Cardiol 1998;82(12):1535-1539.

4. Celermajer DS, Sorensen KE, Gooch VM, Spiegelhalter DJ, Miller OI, Sullivan ID, et al. Non-invasive detection of endothelial dysfunction in children \& adults at risk of atherosclerosis. Lancet 1992; 340(8828):1111-1115.

5. Zawar SD, Vyawahare MA, Nerkar M and Jawahirani AR. Noninvasive Detection of Endothelial Dysfunction in Sickle Cell Disease by Doppler Ultrasonography, J Assoc Physc India 2005; 53: 677-680.

6. Blum A, Yeganeh S, Peleg A, Vigder F, Kryuger K, Khatib A, et al. Endothelial function in patients with sickle cell anemia during and after sickle cell crises. J Thromb Thrombolysis 2005 ; 19(2):83-86.

7. Aessopos A, Farmakis D, Tsironi M, Diamanti-Kandarakis E, Matzourani M, Fragodimiri C, et al. Endothelial function and arterial stiffness in sickle-thalassemia patients. Atherosclerosis 2007; 191(2):427-432.

8. Rambaran C, Jiang B, Ritter JM, Shah A, Kalra Land Chowienczyk PJ. Assessment of endothelial function: comparison of the pulse wave response to $\beta 2$-adrenoceptor stimulation with flow mediated dilatation. Br J Clin Pharmacol. 2008; 65(2): 238-243.

\footnotetext{
Authors Contribution:

PKR - Study design and drafted manuscript; SSR - statistical analysis and drafted manuscript.

Source of Support: Nil, Conflict of Interest: None declared.
} 